\title{
Não-preferência do ácaro-vermelho, Oligonychus yothersi McGregor (Acari: Tetranychidae), para oviposição em folhas de progênies de erva-mate (Ilex paraguariensis)
}

\author{
Non-preference of the red mite Oligonychus yothersi McGregor \\ (Acari: Tetranychidae) for oviposition on leaves of Paraguay tea \\ progenies (Ilex paraguariensis)
}

\author{
Luis Francisco Angeli Alves ${ }^{1 *}$; Cristhiane Rohde ${ }^{2}$; \\ Dayanne Fabrício Bressan ${ }^{3}$; José Djair Vendramim ${ }^{4}$
}

Resumo

\begin{abstract}
A preferência para oviposição do ácaro-vermelho, Oligonychus yothersi McGregor, foi avaliada em condições de laboratório em 52 progênies de erva-mate e uma testemunha coletada em uma propriedade da região. Os experimentos foram realizados em discos foliares de erva-mate ( $2 \mathrm{~cm}$ de diâmetro), infestados com uma fêmea adulta do ácaro, e incubados a $25 \pm 1^{\circ} \mathrm{C}$ e $14 \mathrm{~h}$ de fotofase, durante cinco dias. As avaliações foram realizadas diariamente, contando-se o número de ovos depositados no período, número de fêmeas que fugiram nas primeiras 48 horas e número de ovos depositados antes da fuga. Verificou-se que houve discriminação do ácaro em dois grupos de progênies, em relação ao número de ovos, um que diferiu em relação à testemunha ( $53,8 \%$ de progênies) e outro que se igualou à mesma ( $46,2 \%$ das progênies). No primeiro grupo, houve menor oviposição em $60,7 \%$ das progênies, enquanto que em cerca de $39,3 \%$ ocorreu maior oviposição (média de 3,1 ovos/fêmea). Em 57,7\% das progênies houve fuga das fêmeas (10 a 40\%), sendo que em 10 dessas progênies não ocorreu oviposição antes da fuga. Os dados indicam que em algumas das progênies de erva-mate testadas há resistência por não-preferência para oviposição ao ácaro-vermelho.
\end{abstract}

Palavras-chave: Planta resistente, manejo integrado de pragas, erva-mate

\begin{abstract}
The oviposition preference of the red mite Oligonychus yothersi McGregor was evaluated under laboratory in 52 Paraguay tea progenies and one control collected in a local farm. The experiments were conducted on Paraguay tea leaf discs infested with one adult female mite/disc, incubated in a climate chamber $\left(25 \pm 1^{\circ} \mathrm{C}, 14 \mathrm{~h}\right.$ photophase) for five days. Evaluations were performed daily, by counting the number of eggs laid in the period, the number of female escapes in the first 48 hours, as well as the number of eggs laid before the escaping. It was verified that discrimination by the mite occurred on two groups of progenies, in relation to the number of eggs: one group was different from the control $(53.8 \%$ of the
\end{abstract}

\footnotetext{
1 Universidade Estadual do Oeste do Paraná, Campus de Cascavel, Laboratório de Zoologia, Cascavel, PR, Bolsista de Produtividade em Pesquisa/CNPq. E-mail: 1faalves@unioeste.br.

2 Programa de Pós-Graduação em Entomologia, Universidade Federal de Lavras, Depto. de Entomologia.

3 Programa de Pós-Graduação em Agronomia, Universidade Estadual do Oeste do Paraná, Centro de Ciências Agrárias

4 Universidade de São Paulo, Escola Superior de Agricultura Luiz de Queiroz, Depto. de Entomologia, Fitopatologia e Zoologia Agrícola, Piracicaba-SP.

* Autor para correspondência
} 
progenies) and the other was identical to it (46.2\% of the progenies). In the first group, $60.7 \%$ of progenies were less oviposited while a higher number of eggs/female than the control was verified in $39.3 \%$ of them. In $57.7 \%$ of progenies there was escape of some mites (10 to $40 \%$ ), and in 10 of these progenies no eggs were laid. The data provide evidences that in some of the progenies evaluated there is resistance by non-preference to oviposition of the Paraguay tea red mite.

Key words: Resistant plant, integrated pest management, Paraguay tea

\section{Introdução}

A erva-mate, Ilex paraguariensis St. Hil. (Aquifoliaceae) é uma planta típica das regiões subtropicais e temperadas da América do Sul, e no Brasil é encontrada nos estados da região $\mathrm{Sul}$ associada às formações vegetais naturais, como florestas de araucária, onde era explorada por meio do extrativismo (ANUÁRIO..., 1999; MAZUCHOWSKI; MACCARI JÚNIOR; BRACHT, 2000).

O Brasil é o segundo maior produtor mundial, com cerca de 700 mil ha concentrados no Estado do Paraná, onde apresenta grande importância econômica, sócio-cultural e ambiental (ANUÁRIO..., 1999). Suas folhas e ramos são matéria-prima para o preparo de chimarrão, tererê, chás, pós-solúveis e refrescos, apresentando ainda potencial de uso como matéria-prima para pigmentos, vernizes, desinfetantes etc. (MAZUCHOWSKI; MACCARI JÚNIOR; BRACHT, 2000).

Durante a década de 1970, a expansão da agricultura na região Sul do Brasil alterou a paisagem natural e muitos ervais nativos desapareceram, e desta forma a erva-mate passou a ser cultivada em regime de monocultura, diferente do ambiente no qual evoluiu e se adaptou. Com a alteração do ecossistema, a densidade de plantas aumentou e a diversidade biológica diminuiu e, como conseqüência, algumas espécies passaram a apresentar elevados níveis populacionais e assumiram o status de pragas (IEDE, 1985; PENTEADO, 1995).

Dentre estas, destacam-se três espécies de ácaros fitófagos, sendo o ácaro-do-bronzeado Dichopelmus notus Keifer (Eryophiidae), o ácaro-vermelho Oligonychus yothersi (McGregor) (Tetranychidae) e o ácaro-branco Polyphagotarsonemus latus
(Banks) (Tarsonemidae). Os dois primeiros são mais comumente encontrados no campo, enquanto o último é mais freqüente nos viveiros de mudas (SANTANA et al., 1997; FERLA; MARCHETTI; SIEBERT, 2005).

Os ácaros danificam as plantas durante a alimentação, quando destroem os tecidos ou inoculam toxinas nas folhas, sendo que especificamente na erva-mate, há a possibilidade de entrada de fungos fitopatogênicos nas áreas danificadas, visto que tais microrganismos foram isolados das áreas necróticas de folhas desta planta (FLECHTMANN, 1979; CHIARADIA; MILANEZ, 1998).

Alves et al. (2004) verificaram que os danos de $O$. yothersi inicialmente surgem como pontuações arroxeadas nas folhas, que evoluem para áreas necróticas. Além disso, as folhas infestadas apresentam-se deformadas e com o desenvolvimento retardado em relação às folhas não danificadas e caem precocemente. Ainda, segundo os autores e, corroborando informações obtidas em laboratório por Silva, Gassen e Alves (2001), todos os estágios de $O$. yothersi encontram-se, preferencialmente na superfície adaxial das folhas, tanto para oviposição como para alimentação.

$\mathrm{Na}$ Argentina, estudos com ácaros-praga da ervamate estão mais avançados, principalmente em relação à dinâmica populacional e controle nas principais regiões produtoras (DE COLL; CACERES, 1995). Contudo, no Brasil, os estudos sobre o ácaro vermelho da erva-mate se referem a detalhes de comportamento (SILVA; GASSEN; ALVES, 2001), biologia e danos (ALVES et al., 2004) e controle biológico com fungos entomopatogênicos (OLIVEIRA; ALVES; NEVES, 2002; OLIVEIRA; NEVES; ALVES, 2004), sendo necessários estudos 
que visem alternativas para o controle da praga, haja vista que no Brasil proibe-se o uso de acaricidas químicos na cultura da erva-mate.

Neste contexto, este trabalho foi realizado com o objetivo de avaliar, em condições de laboratório, a não-preferência de $O$. yothersi, para oviposição em diferentes progênies de erva-mate selecionadas pela Embrapa Florestas, visando fornecer subsídios para trabalhos de melhoramento genético da cultura, no desenvolvimento de cultivares resistentes à praga.

\section{Material e Métodos}

Os experimentos foram realizados com 52 progênies de erva-mate fornecidas pela Embrapa Florestas, provenientes da coleção daquela Instituição, sendo transferidas para vasos plásticos de $20 \mathrm{~L}$ de capacidade, e mantidas no interior de casa-de-vegetação, no Campus da Unioeste, em Cascavel, PR, durante seis meses. Cada progênie foi considerada um tratamento. As plantas que constituíram a testemunha foram obtidas de um produtor comercial de Cascavel, PR, sendo todas de mesma origem, e não apresentavam denominação de genótipo.

Devido à grande quantidade de plantas a ser avaliada, optou-se pela formação aleatória de grupos, e assim, as progênies foram divididas, ao acaso, em 13 grupos, constituídos de quatro progênies, sempre acompanhadas da testemunha.

Para cada avaliação, com base na técnica proposta por Oliveira, Alves e Neves (2001) foram utilizados 10 discos foliares de cada progênie, com 2 cm de diâmetro, extraídos de folhas maduras (originadas no ano anterior), sendo colocados com a superfície adaxial voltada para cima, em uma placa de Petri, sobre uma camada de algodão hidrófilo umedecido, constituindo, cada conjunto, uma repetição. Em seguida, uma fêmea adulta, com três dias de idade, proveniente da criação estoque mantida em laboratório, foi transferida para cada disco.
As placas foram mantidas a $25 \pm 1^{\circ} \mathrm{C}$, U.R. $70 \pm 10 \%, 14 \mathrm{~h}$ de fotofase, durante cinco dias, período em que os discos foliares se mantêm adequados aos ácaros (OLIVEIRA; ALVES; NEVES, 2001). Nesse período, foi avaliado diariamente o número de ovos por disco. Nas primeiras $48 \mathrm{~h}$ também foi contado o número de fêmeas que fugiram dos discos e o número de ovos colocados antes da fuga.

Os experimentos foram conduzidos segundo o delineamento estatístico inteiramente casualizado, sendo os dados analisados estatisticamente quanto à variância (teste $F, p \leq 0,05$ ) e as médias de ovos/disco comparadas com a testemunha pelo teste de Dunnet bilateral $(\mathrm{P}<0,05)$, utilizando o programa estatístico Sanest (MACHADO; ZONTA, 1991).

\section{Resultados e Discussão}

Houve discriminação pelas fêmeas do ácarovermelho quanto à oviposição. Em 28 progênies $(53,8 \%)$ constatou-se diferença significativa em relação à respectiva testemunha, com oviposição média de 1,8 ovos/fêmea. Desse grupo, em 17 progênies $(60,7 \%)$ a oviposição foi menor que na testemunha, com número médio de ovos por fêmea igual à 1,0 , enquanto que em 11 progênies $(39,3 \%)$ a oviposição foi maior que na testemunha, com oviposição média de 3,14 ovos por fêmea. Para as 24 progênies restantes (que representaram $46,2 \%$ do total), não se observou diferença significativa quanto ao número de ovos em relação à testemunha (Tabela 1).

Ainda que possa ter ocorrido alguma interferência da qualidade dos discos no comportamento de oviposição, ressalta-se que a técnica adotada no presente trabalho foi desenvolvida e testada previamente em estudos de biologia, comportamento e seleção de isolados de fungos entomopatogênicos com esta mesma espécie de ácaros, sendo igualmente utilizada para manutenção da criação estoque em laboratório por várias gerações (SILVA; GASSEN; ALVES, 2001; OLIVEIRA; ALVES; NEVES, 2002; OLIVEIRA; NEVES; ALVES, 2004; ALVES et al., 2004). 
Diferenças na oviposição também foram observadas por Silva, Lourenção e Moraes (1992), confinando fêmeas de Tetranychus evansi em discos foliares de diferentes genótipos de tomateiro. De acordo com estes autores, houve grande variação na oviposição média, sendo que aqueles com menor números de ovos ( 0 e 2 ovos) foram considerados resistentes em relação àqueles onde as fêmeas ovipositaram mais (acima de 3,6 ovos).

Por outro lado, Lourenção et al. (2000), confinando fêmeas em folhas visando avaliar a resistência do morangueiro ao ácaro $T$. urticae, não constataram diferença no número de ovos/fêmea, nos diferentes clones da planta, o que evidencia que essa técnica não permitiu a discriminação entre genótipos.

Silva, Gassen e Alves (2001), confinando fềmeas de $O$. yothersi por um período de $48 \mathrm{~h}$ em discos foliares de erva-mate, obtiveram, em média, 17 ovos por disco, ressaltando-se, entretanto, que foram confinadas 15 fêmeas/disco e, desta forma, o número de ovos/fêmea foi de 1,1, inferior à média ( 1,8 ovos/ fêmea), fato também registrado no presente trabalho.

Observou-se ainda que dentre as 24 progênies $(54,2 \%)$ que não diferiram significativamente da testemunha $(1,2,5,8,16,17,22,23,24,26,28,30$, $31,32,33,34,40,42,46,47,49,50,52$ e T) em relação ao número de ovos, em 13 delas $(1,16,17$, $21,24,29,31,34,40,42,47,52 \mathrm{e} \mathrm{T})$, houve fuga das fêmeas, e em seis destas não houve oviposição antes da fuga $(1,17,24,42,52 \mathrm{e} T)$. No percentual restante das progênies $(45,8 \%$, correspondendo a 11 progênies), não houve fuga das fêmeas, porém, em nenhuma delas houve oviposição, confirmando assim, uma provável existência de fatores de resistência que levaram à não-preferência das fêmeas do ácaro para oviposição.

Tabela 1. Oviposição média, porcentagem de fuga de fêmeas, e média de ovos colocados pelas fêmeas do ácarovermelho (Oligonychus yothersi) em discos foliares de erva-mate (Ilex paraguariensis), em condições de laboratório (Temp.: $25 \pm 1^{\circ} \mathrm{C}$, U.R.: $70 \pm 10 \%$, fotofase: $14 \mathrm{~h}$ ).

\begin{tabular}{|c|c|c|c|c|}
\hline $\begin{array}{c}\mathrm{N}^{0} \text { do } \\
\text { Experimento }\end{array}$ & Progênie & $\begin{array}{l}\text { № médio de } \\
\text { ovos/fêmea }{ }^{1}\end{array}$ & $\begin{array}{l}\text { Porcentagem de fuga } \\
(\mathrm{n}=10)\end{array}$ & $\begin{array}{l}\text { № médio de ovos/fêmea } \\
\text { antes da fuga }\end{array}$ \\
\hline \multirow{5}{*}{1} & Testemunha & 3,3 & 0 & - \\
\hline & 8 & $3,0 \mathrm{NS}^{1}$ & 0 & - \\
\hline & 20 & $2,8^{*}$ & 0 & - \\
\hline & 29 & $1,6^{*}$ & 20 & 0,5 \\
\hline & 21 & $0,6^{*}$ & 20 & 0 \\
\hline \multirow{5}{*}{2} & Testemunha & 4,2 & 0 & - \\
\hline & 50 & $3,5 \mathrm{NS}$ & 10 & 2,5 \\
\hline & 28 & $3,4 \mathrm{NS}$ & 20 & 1,5 \\
\hline & 9 & $0,5^{*}$ & 20 & 2 \\
\hline & 39 & $0,3^{*}$ & 10 & 0,5 \\
\hline \multirow{5}{*}{3} & Testemunha & 3,6 & 0 & - \\
\hline & 22 & $4,1 \mathrm{NS}$ & 0 & - \\
\hline & 46 & $3,6 \mathrm{NS}$ & 0 & - \\
\hline & 49 & $3,5 \mathrm{NS}$ & 0 & - \\
\hline & 44 & $2,1^{*}$ & 0 & - \\
\hline \multirow{5}{*}{4} & Testemunha & 2,3 & 0 & - \\
\hline & 23 & $2,7 \mathrm{NS}$ & 0 & - \\
\hline & 19 & $1,0^{*}$ & 0 & - \\
\hline & 10 & $1,0^{*}$ & 10 & 1,5 \\
\hline & 3 & $0,5^{*}$ & 30 & 1 \\
\hline
\end{tabular}


continuação

\begin{tabular}{|c|c|c|c|c|}
\hline $\begin{array}{c}\mathrm{N}^{\circ} \text { do } \\
\text { Experimento }\end{array}$ & Progênie & $\begin{array}{l}\text { № médio de } \\
\text { ovos/fêmea }^{1}\end{array}$ & $\begin{array}{l}\text { Porcentagem de fuga } \\
\quad(\mathrm{n}=10)\end{array}$ & $\begin{array}{c}\text { № médio de ovos/fêmea } \\
\text { antes da fuga }\end{array}$ \\
\hline \multirow{5}{*}{5} & Testemunha & 0,7 & 0 & - \\
\hline & 14 & $4,9 *$ & 0 & - \\
\hline & 27 & $4,6^{*}$ & 10 & 8 \\
\hline & 16 & $1,5 \mathrm{NS}$ & 30 & 2,3 \\
\hline & 17 & $0,9 \mathrm{NS}$ & 30 & 0 \\
\hline \multirow{5}{*}{6} & Testemunha & 1,1 & 0 & - \\
\hline & 48 & $4,1 *$ & 0 & - \\
\hline & 11 & $2,1^{*}$ & 10 & 5 \\
\hline & 2 & $1,5 \mathrm{NS}$ & 0 & - \\
\hline & 47 & $1,0 \mathrm{NS}$ & 20 & 0,5 \\
\hline \multirow{5}{*}{7} & Testemunha & 0,7 & 0 & - \\
\hline & 41 & $3,7^{*}$ & 10 & 0 \\
\hline & 35 & $2,8^{*}$ & 10 & 0 \\
\hline & 12 & $2,8^{*}$ & 0 & - \\
\hline & 43 & $2,7^{*}$ & 0 & - \\
\hline \multirow{5}{*}{8} & Testemunha & 3,9 & 0 & - \\
\hline & 32 & $4,1 \mathrm{NS}$ & 0 & - \\
\hline & 34 & $3,2 \mathrm{NS}$ & 30 & 1 \\
\hline & 42 & $3 \mathrm{NS}$ & 40 & 0 \\
\hline & 4 & $1,2 *$ & 0 & - \\
\hline \multirow{5}{*}{9} & Testemunha & 0,2 & 0 & - \\
\hline & 7 & $3,2^{*}$ & 10 & 3 \\
\hline & 18 & $2,2 *$ & 20 & 7 \\
\hline & 6 & $1,4^{*}$ & 0 & - \\
\hline & 31 & $0,0 \mathrm{NS}$ & 10 & 1 \\
\hline \multirow{5}{*}{10} & Testemunha & 3,2 & 0 & - \\
\hline & 5 & $3,4 \mathrm{NS}$ & 0 & - \\
\hline & 33 & $2,5 \mathrm{NS}$ & 0 & - \\
\hline & 52 & $2,5 \mathrm{NS}$ & 20 & 0 \\
\hline & 37 & $0,3^{*}$ & 30 & 0,7 \\
\hline \multirow{5}{*}{11} & Testemunha & 3,4 & 0 & - \\
\hline & 40 & $3,0 \mathrm{NS}$ & 10 & 2 \\
\hline & $\mathrm{T}$ & 2,9 NS & 10 & 0 \\
\hline & 45 & $1,1^{*}$ & 20 & 2 \\
\hline & 13 & $0,7 *$ & 0 & - \\
\hline \multirow{5}{*}{12} & Testemunha & 3,4 & 0 & - \\
\hline & 1 & $2,9 \mathrm{NS}$ & 10 & 0 \\
\hline & 24 & $2,8 \mathrm{NS}$ & 10 & 0 \\
\hline & 25 & $0^{*}$ & 30 & 0,6 \\
\hline & 51 & $0 *$ & 20 & 0,5 \\
\hline \multirow{5}{*}{13} & Testemunha & 3,3 & 0 & - \\
\hline & 26 & $2,7 \mathrm{NS}$ & 0 & - \\
\hline & 30 & $2,6 \mathrm{NS}$ & 0 & - \\
\hline & 15 & $2,0^{*}$ & 10 & 0 \\
\hline & 38 & $1,6^{*}$ & 0 & - \\
\hline
\end{tabular}

${ }^{1}$ considerando todas as fêmeas avaliadas.

*Médias que diferiram significativamente da respectiva testemunha, segundo o teste de Dunnet bilateral ( $\mathrm{P} \leq 0,05)$. 
Confrontando-se os dados de porcentagem de fuga de fêmeas e o número médio de ovos postos por estas antes da fuga, verificou-se que a média de ovos colocados por estas fêmeas variou de nenhum ovo (progênie 42), em que 40\% das fêmeas fugiram, até um valor médio de 1,7 ovos, obtido nas progênies que tiveram $10 \%$ de fuga das fêmeas (Tabela 2).

Tabela 2. Porcentagem de fuga de fêmeas do ácaro-vermelho (Oligonychus yothersi) e respectiva média de ovos colocados pelas fêmeas antes da fuga em discos foliares de erva-mate (Ilex paraguariensis), em condições de laboratório (Temp.: $25 \pm 1^{\circ} \mathrm{C}$, U.R.: $70 \pm 10 \%$, fotofase: $14 \mathrm{~h}$ ).

\begin{tabular}{ccc}
\hline Porcentagem de fuga de fêmeas & $\begin{array}{c}\text { Total de progênies que } \\
\text { apresentaram fuga de fêmeas }\end{array}$ & Média de ovos/fêmea antes da fuga \\
\hline 10 & 14 & 1,7 \\
20 & 9 & 1,6 \\
30 & 6 & 1,0 \\
40 & 1 & 0,0 \\
\hline
\end{tabular}

Nas progênies em que houve fuga de fêmeas, verificou-se que o número médio não ultrapassou 3 ovos, exceto para as progênies 11 e 27 (5 e 8 ovos, respectivamente), nas quais ocorreram $10 \%$ de fuga e para a progênie 18 ( 7 ovos), na qual houve $20 \%$ de fuga (Tabela 1).

Nas progênies em que se verificou fuga de $10 \%$ das fêmeas, houve maior variação na oviposição, sendo que em cinco progênies $(7,11,27,40$ e 50) o número de ovos por fêmea antes da fuga superou a média de $1,7(3,5,8,2$ e 2,5 ovos/fêmea, respectivamente).

Utilizando a técnica de confinamento em plantas em casa-de-vegetação, Lourenção et al. (2000) verificaram que apesar de não haver diferença no número de ovos colocados por fêmeas de T. urticae nas folhas dos diferentes clones de morangueiro, foi verificada preferência dos ácaros por alguns clones para colonização, sendo que aqueles que apresentaram menor número de indivíduos foram considerados menos adequados para o desenvolvimento populacional do ácaro.

Explicar as diferenças obtidas no presente trabalho torna-se difícil, pois ao contrário de muitas plantas cultivadas, para a erva-mate nada é relatado na literatura sobre causas/fontes físicas e químicas de resistência a pragas, a não ser a presença de saponinas, que de acordo com Potter e Kimmerer (1989), estão presentes em maior concentração nas folhas jovens de plantas do gênero Ilex em relação às folhas maduras. Ainda segundo esses autores, tais substâncias conferem às plantas relativa proteção contra o ataque de algumas espécies de artrópodos fitófagos, como é o caso de ácaros tetraniquídeos. Contudo, não é possível extrapolar esta condição para todas as outras espécies de ácaros e insetos fitófagos que ocorrem na cultura da erva-mate.

No que se refere à presente pesquisa, as saponinas, se presentes, estariam correndo em baixa concentração, já que foram utilizadas folhas maduras e se encontravam no mesmo estágio de desenvolvimento, ou seja, surgidas no ano anterior à realização do experimento, e que, segundo os autores citados anteriormente, estariam apresentando menor concentração de saponinas.

Além disso, todas as progênies, incluindo a testemunha, apresentavam igual tamanho e foram transplantadas seis meses antes da realização do experimento para vasos contendo o mesmo tipo de solo e igual quantidade de adubação orgânica (esterco curtido de aves) e receberam o mesmo volume de água na irrigação, tornando praticamente inexistente a possibilidade de que fatores nutricionais pudessem se caracterizar como fonte de resistência, interferindo no comportamento ou fisiologia do ácaro. 
Assim, os dados obtidos na presente pesquisa evidenciam que nas plantas de erva-mate há resistência por não-preferência para oviposição ao ácaro-vermelho, o que justifica a realização de mais estudos sobre o assunto em programas de seleção de progênies de erva-mate, visando ao controle dessa praga.

\section{Agradecimentos}

Ao CNPq pela concessão de bolsa de produtividade em pesquisa e de iniciação científica, à Fundação Araucária pela concessão de auxílio financeiro para a realização do projeto de pesquisa e à Embrapa Florestas pelo fornecimento das mudas e auxílio financeiro.

\section{Referências}

ALVES, L. F. A.; SPONGOSKI, S.; SILVA, F.N.; MORAES, G J. Biologia e danos de Oligonychus yothersi (McGregor) (Acari, Tetranychidae) em Ilex paraguariensis. Arquivos do Instituto Biológico, São Paulo, v.71, n.2, p.211-214, 2004.

ANUÁRIO brasileiro de erva-mate. Santa Cruz do Sul: Pallotti, 1999.

CHIRADIA, L. A.; MILANEZ, J. M. Localização do "ácaro-do-bronzeado" Dichopelmus notus Keifer (Acari: Eriophyidae) e causas do dano na planta de erva-mate. In: CONGRESSO BRASILEIRO DE ENTOMOLOGIA, 16. , 1998, Rio de Janeiro. Anais... Rio de Janeiro: FIOCRUZ, 1998.p.1037.

DE COLL, O. R.; CÁCERES, M. S. Determinación de la fluctuación poblacional del "ácaro del bronceado" de la yerba mate y sus enemigos naturales. In: WINGE, H.; FERREIRA, A. G.; MARIATH, J. E. A.; TARASCONI, L. C. (Org.) Erva-mate: biologia e cultura no Cone Sul. Porto Alegre: Ed. UFRGS, 1995. p.121-128.

FERLA, N. J.; MARCHETTI, M. M.; SIEBERT, J. C. Acarofauna (Acari) de erva-mate (Ilex paraguariensis St. Hil.: Aqüifoliaceae) no estado do Rio Grande do Sul. Biociências, Porto Alegre, v.13, n.2, p.133-142, 2005.

FLECHTMANN, C. H. W. Ácaros de importância agrícola. São Paulo: Nobel, 1979.

IEDE, E. T. Considerações sobre a entomofauna da ervamate (Ilex paraguariensis St. Hill.). In: SEMINÁRIOS SOBRE ATUALIDADES E PERPECTIVAS FLORESTAIS SILVICULTURA DA ERVA-MATE (ILEX PARAGUARIENSIS ST. HILL.), 10., 1983, Curitiba. Resumos... Curitiba: Embrapa, 1985. p.111-118.
LOURENÇÃO, A. L.; MORAES, G. J.; PASSOS, F. A.; AMBROSANO, G. M. B.; SILVA, L. V. F. Resistência de morangueiros a Tetranychus urticae Koch (Acari: Tetranychidae). Anais da Sociedade Entomológica do Brasil, Londrina, v.29, n.2, p.339-346, 2000.

MACHADO, A. A.; ZONTA, E. P. Manual do Sanest: sistema de análise estatística para microcomputadores. Pelotas: UFPel, 1991.

MAZUCHOWSKI, J. Z.; MACCARI JÚNIOR, A.; BRACHT, M. J. Normativos legais para pesquisas tecnológicas na cadeia produtiva da erva-mate. Curitiba: Câmara Setorial da Cadeia Produtiva da Erva-Mate do Paraná, 2000.

OLIVEIRA, R. C.; ALVES, L. F. A.; NEVES, P. M. O. J. Suscetibilidade de Oligonychus yothersi (Acari: Tetranychidae) ao fungo Beauveria bassiana. Scientia Agricola, Piracicaba, v.59, n.1, p.187-189, jan./mar. 2002.

. Técnica para desenvolvimento de bioensaios com Oligonychus yothersi (Acari: Tetranychidae) em laboratório. Arquivos do Instituto Biológico, São Paulo, v.68, n.2, p.125-126, 2001.

OLIVEIRA, R. C.; NEVES, P. M. O. J.; ALVES, L. F. A. Seleção de fungos entomopatogênicos para controle de Oligonychus yothersi (McGregor) (Acari: Tetranychidae), na cultura da erva-mate (Ilex paraguariensis St. Hill.). Neotropical Entomology, Vacaria, v.3, n.33, p.347-351, 2004.

PENTEADO, S. R. C. Principais pragas da erva-mate e medidas alternativas para o seu controle. In: WINGE, H.; FERREIRA, A. G.; MARIATH, J. E. A.; TARASCONI, L. C. Erva-mate biologia e cultura no Cone Sul. Porto Alegre: Ed. UFRGS, 1995. p.109-120.

POTTER, D. A.; KIMMERER, T. W. Inhibition of herbivory on young holly leaves: evidence for the defensive role of saponins. Oecologia, Berlin, v.78, p.322-329, 1989.

SANTANA, D. L. Q.; FLECHTMANN, C. H. W.; MILANEZ, J. M.; MEDRADO, M. J. S.; MOSELE, S. H.; CHIARADIA, L. A. Ácaros em erva-mate (Ilex paraguariensis St. Hill.) no Sul do Brasil. Comunicado Técnico, Dourados, v.17, p.1-2,1997.

SILVA, C. A. D.; LOURENÇÃO, A. L.; MORAES, G. J. Resistência de tomateiros ao ácaro vermelho Tetranychus evansi Baker \& Pritchard (Acari: Tetranychidae). Anais da Sociedade Entomológica do Brasil, Jaboticabal, v.21, p.147-156, 1992.

SILVA, E. R. L.; GASSEN, M. H.; ALVES, L. F. A. Estudo do comportamento do ácaro-vermelho, Oligonychus yothersi (Acari, Tetranychidae) em folhas de erva-mate. Scientia Agraria Paranaensis, Marechal Cândido Rondon, v.1, p.11-20, 2001. 
